\title{
Architecture of Cargo Processes Automated Planning System for Container Terminal Railways
}

\author{
Ilya Vasilev and Elena Antonova* \\ 690065, Russia, Vladivostok, Leonova St. 66 - 171, Russia \\ ${ }^{*}$ Corresponding author
}

\begin{abstract}
The article describes the architecture of automated planning system for container terminal railways. Authors describes main tasks which should be solved in domain and describes how these tasks were automated within developed software.
\end{abstract}

Keywords-container terminal management systems; automated planning

\section{INTRODUCTION}

Transportation system has crucial effect for Russia economics. Transport is the most powerful factor for economic growth. Railways in Russia handles more than 75 percent of freight turnover and 40 percent of passenger turnover.

The key branch of cargo transportation within railways is container shipping. This is the most convenient and inexpensive shipping type. Main freight transport ways goes through Saint Petersburg port (35\%), Vostochniy and Vladivostok ports in Far East of Russia (23\%) [1].

Major transport nodes in container shipping are container terminals. Containers are moving from one transport to another there. Railways are the most important transportation type on container terminals.

A cargo operations planning is complicated production process. In view of large amount of information and different factors affecting cargo processes it is often hard to organize this process optimally. Automation is one of modern ways to improve management. Using of informational technologies lets decrease time required to make decisions, increase amount of processing data, gives ability to observe different scenarios of cargo processing and their efficiency. Current level of automation does not give ability to fully use production capacity. This justifies necessity of development new automated planning methods for container terminal railways which allow increasing quality of cargo process planning, decrease container handling time, reduce handling equipment mileage [2].

\section{DOMAIN ANALYSIS}

To develop required software domain "Railways on container terminal" was analyzed and formal model was created. Language of applied logic was used to specify the model. The language is based on the language of the predicate calculus.

The main processes of analyzed domain "Railways on container terminal" are:

- Distribution of railcars to railway fronts

- Stowage zone addresses planning for discharged containers

- Distribution of loaded containers to railcars

These processes affect each other in terms of schedule and outcomes. Depending on which containers are discharged from railcars ability to load further containers is defined. Railcars distribution defines efforts for the following discharge and loading processes. Quality of these processes' outcomes can be measured as time required for moving containers from stowage section to railcar and vice versa. Time has major impact to the overall cargo process. That's why time decreasing can be specified as main goal for analyzed industrial process optimization.

Specify the tasks which should be solved to successfully automate analyzed domain [3]:

- Task 1. Create set of load containers plans

- Subtask 1.1. Check container compatibility by weight and size

- Subtask 1.2. Check railcar compatibility by destination and railcar owner

- Subtask 1.3. Check railcar loading rules

- Task 2. Create set of railcars distributions to put to rail fronts

- Task 3. Create set of stowage zone addresses planning for discharged containers

- Subtask 3.1. Check compatibility by stowage zone and container specifications

- Task 4. Define optimal distribution of railcars from set of generated options

- Subtask 4.1. Calculate distance to move container from stowage section to railcar and vice versa 


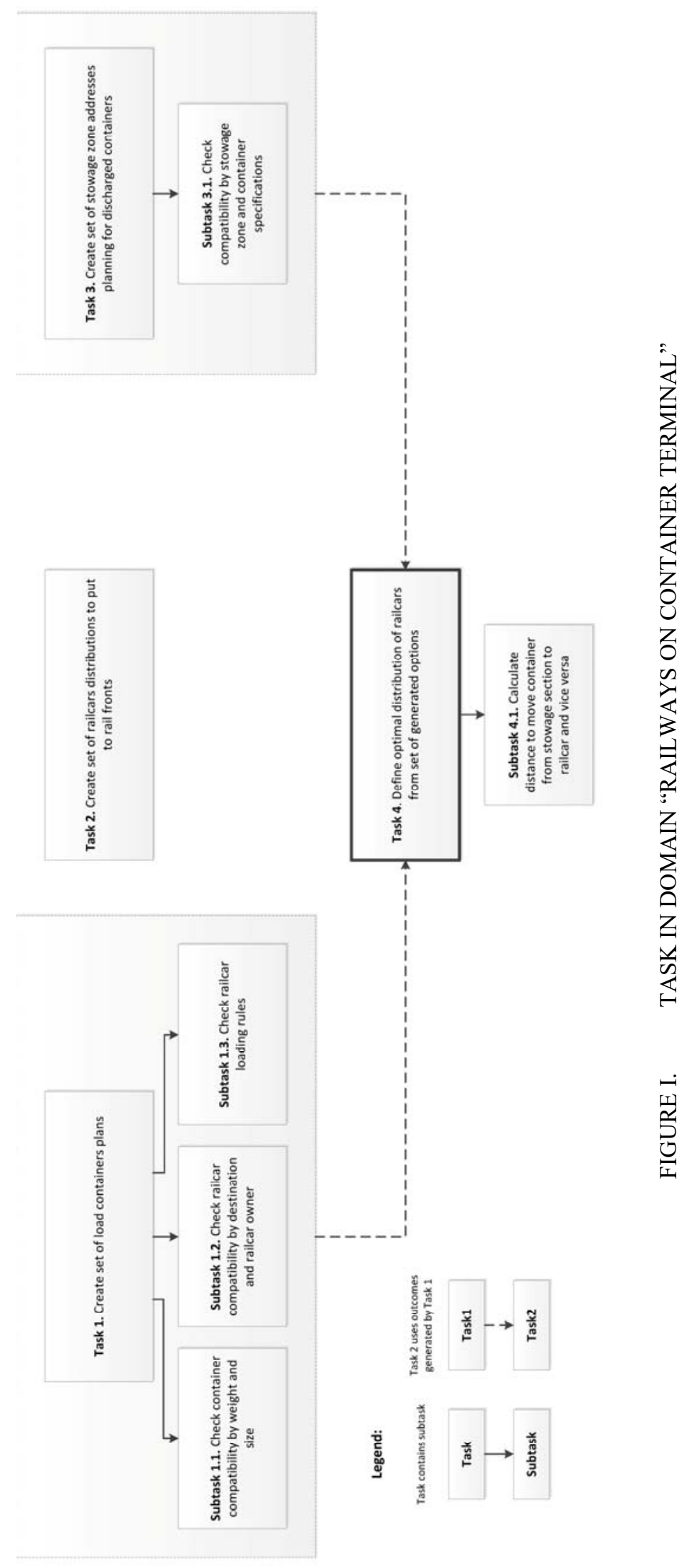


Developed software consists of input/output subsystems, load and discharge planner subsystems and railcar distribution generator subsystem. Knowledge base editors are implemented as well. Input data entered to system within XML format. Based on this the software can be joined existing container terminal management systems. Two knowledge base editors are created: first one describes railcar loading rules, the second one - stowage section specifications. Optimal distribution search module uses outcomes generated by other subsystems and determines the most useful railcar distribution. Output data uses XML formatted structure.

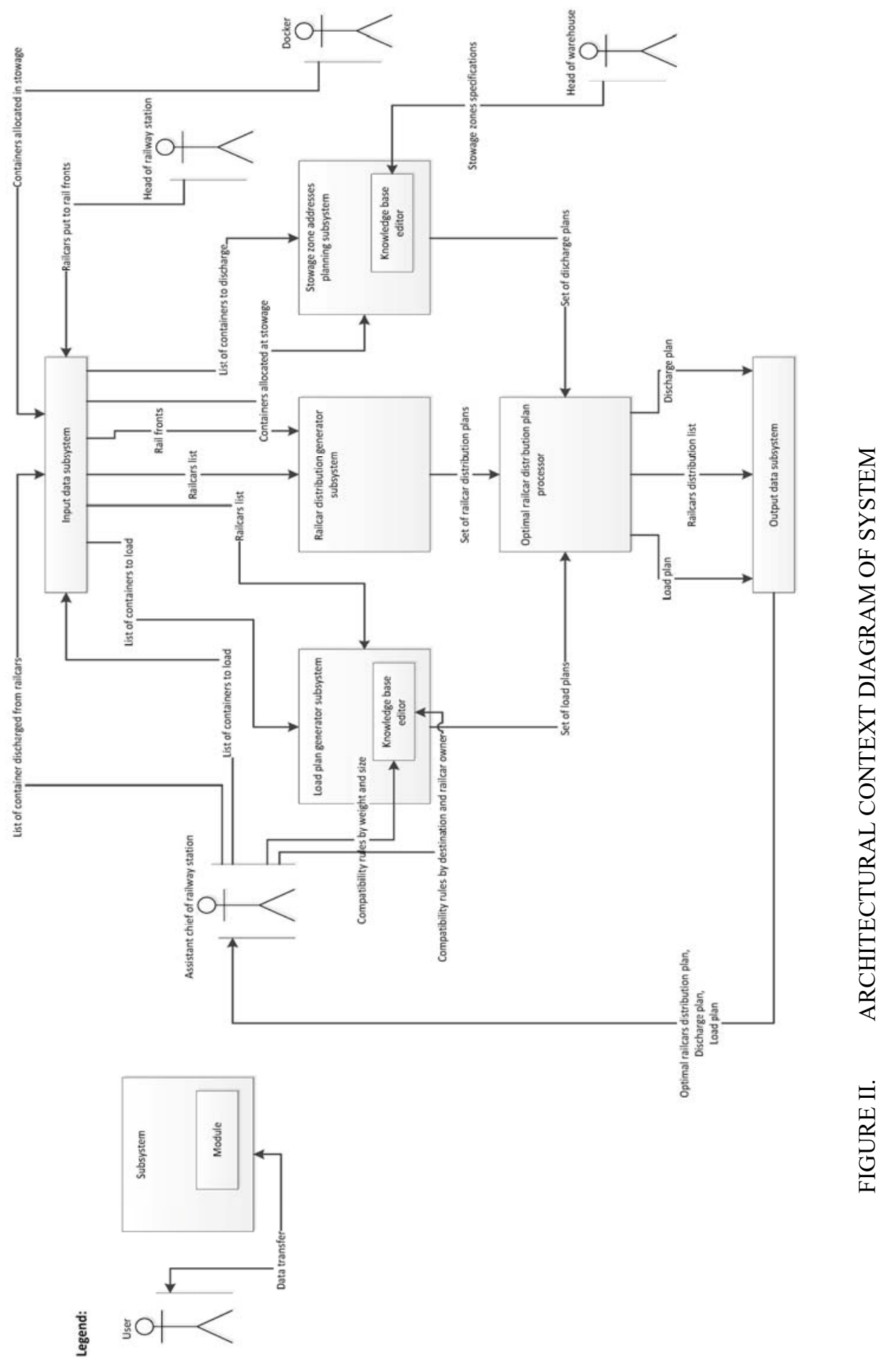


Figure 3 shows load plan generator subsystem. It uses railcar load rules database, railcar owners database and containers and railcars databases. Container-railcar various pair generator was developed based on generator of various combinations for natural numbers from $\mathrm{N}$ to $\mathrm{K}$. The subsystem has several modules which calculate and process the rules entered with knowledge base editors.

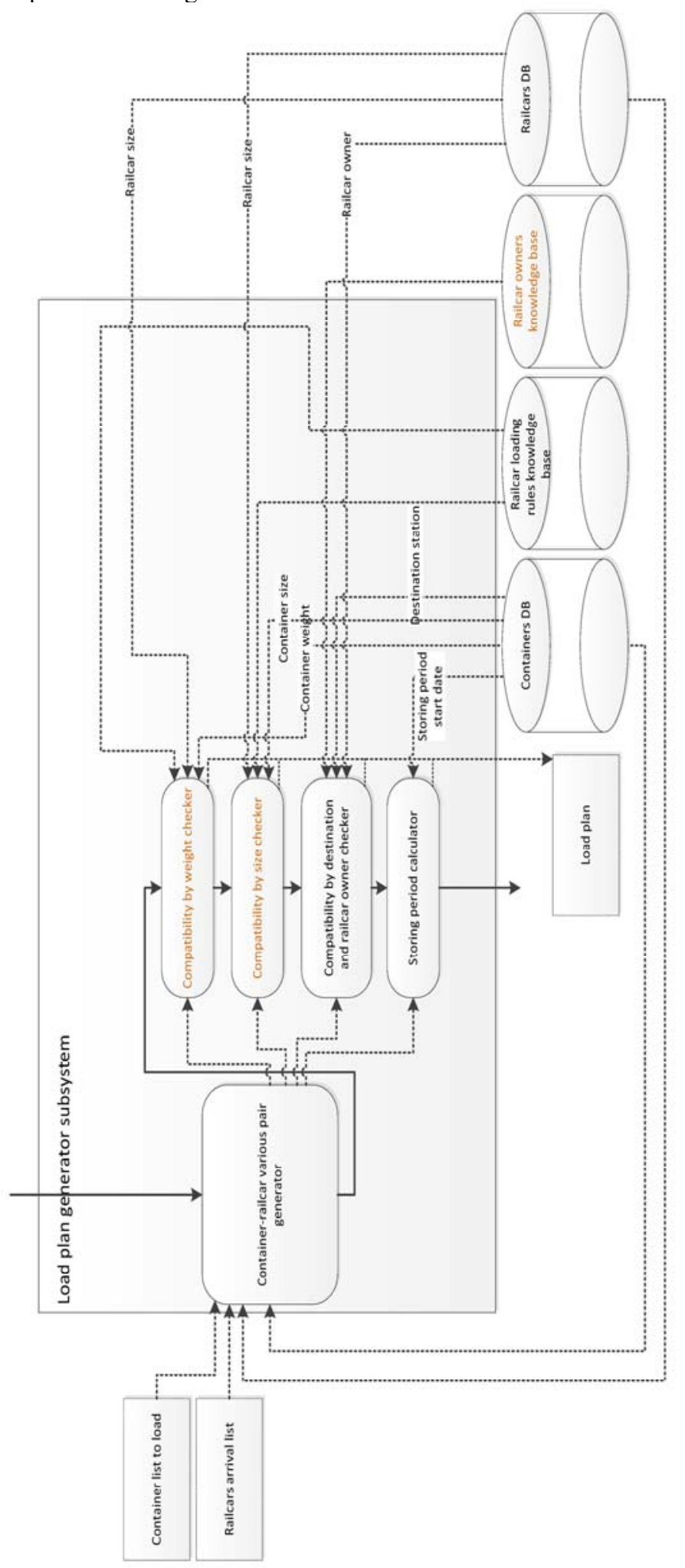

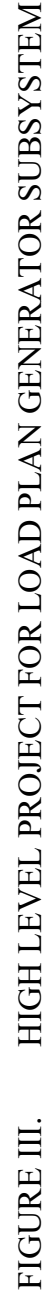


Railcar distribution generator subsystem is shown at figure 4. It contains containers and rail fronts databases. Various railcar distribution generator uses algorithm for natural number decomposition.

Figure 5 contains stowage zone addresses planning subsystem. It has stowage section specification databases.
Container allocation rules are entered using corresponding knowledge base editor. Containers database is used by subsystem as well. Various containers allocation generator produces possible pairs of containers and stowage section places where container could be kept. The subsystem has module which determines compatibility by container and stowage section specifications.

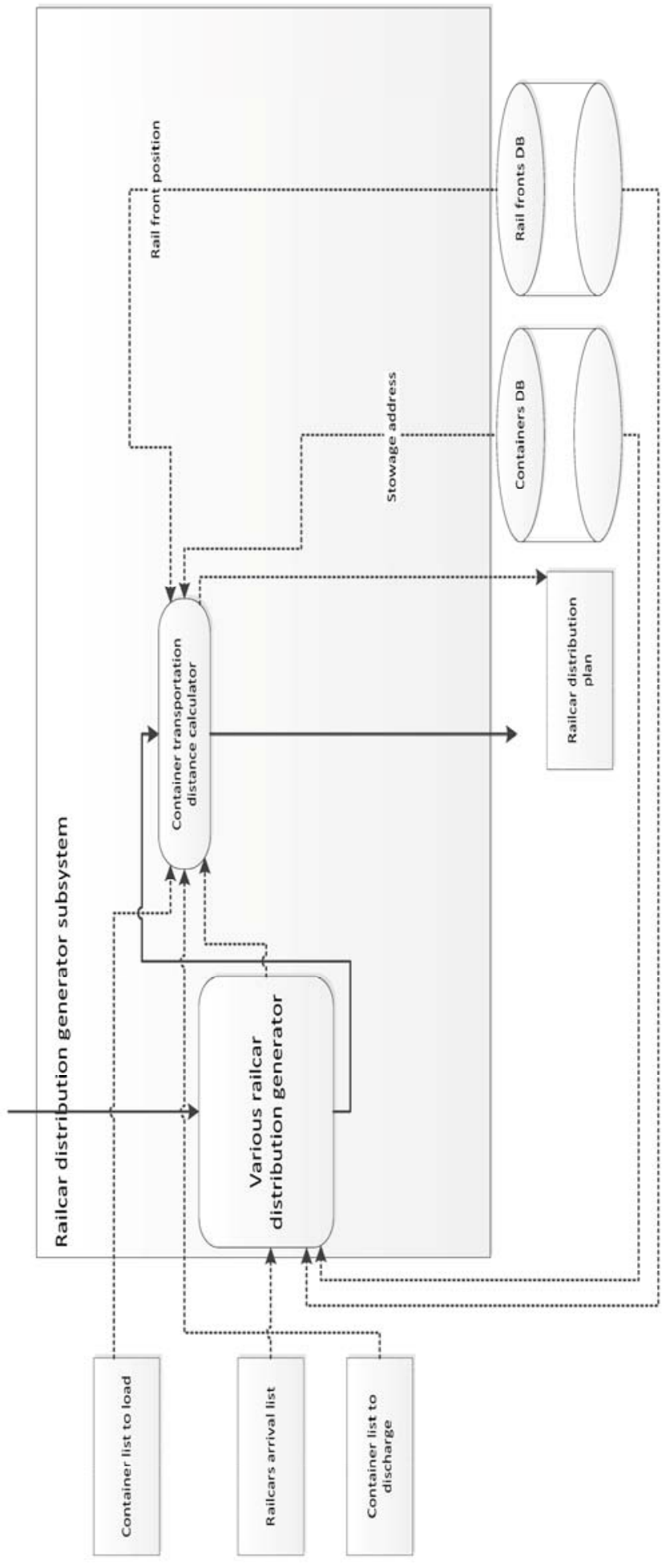

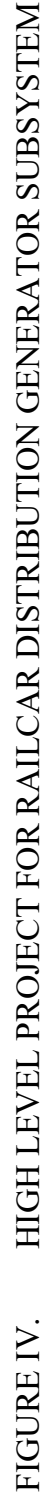




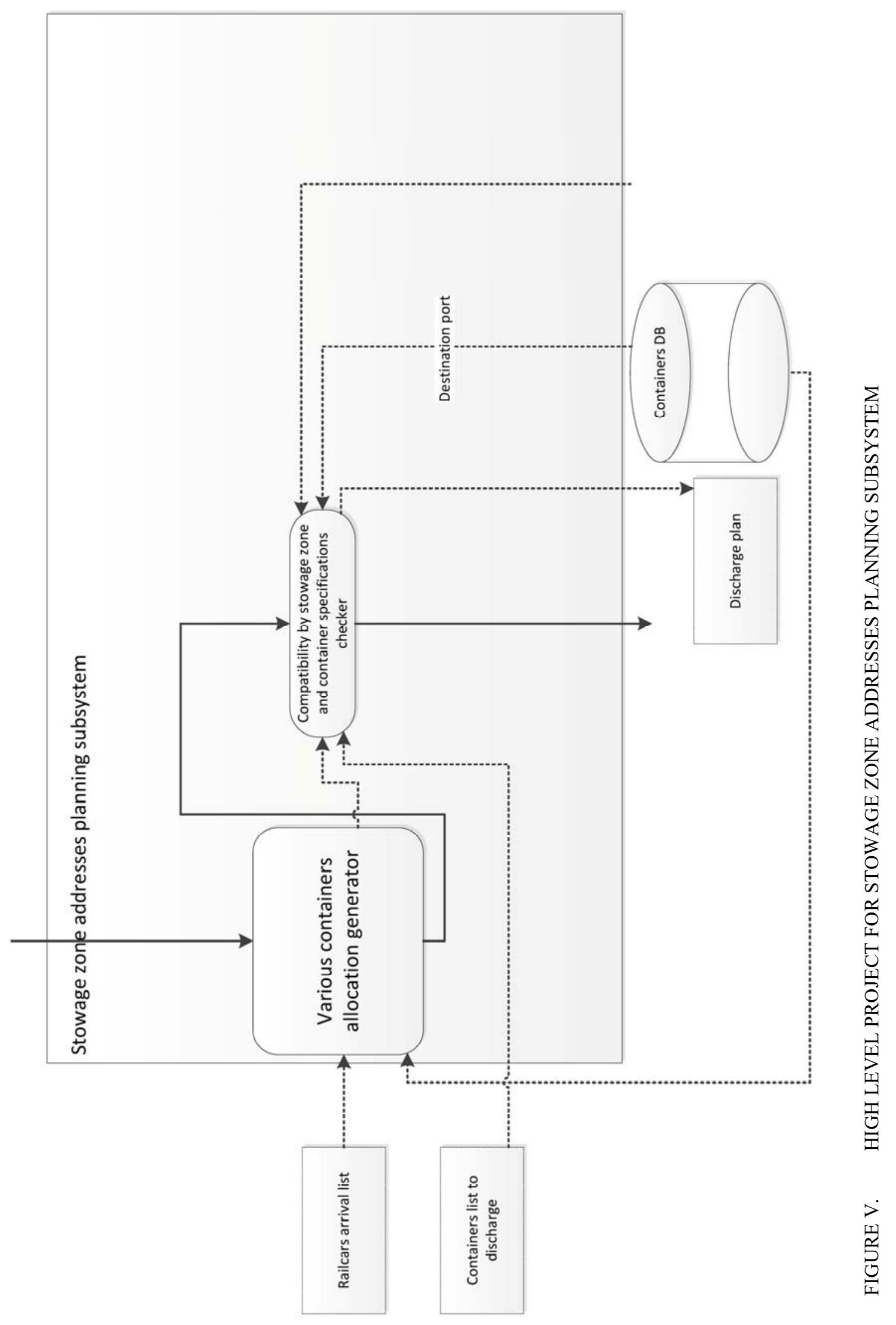


Using of the developed software allows to minimize processing time during cargo operations on container terminal railways, increase efficiency of handling equipment usage. Applied system analysis in cargo processes planning decreases the number of useless container movements, improves time of container loading and discharge, reduces cost of performed cargo operations.

\section{REFERENCES}

[1] Experience of informational technologies usage to manage rail stock and plan railway freight [Electronic resource] Conference: Russian Railways JSC at the transport services market http://www.magnetosoft.ru/index.php?id=42

[2] E. Antonova, I. Vasilev. The problem of cargo processes management on container terminal railways. Scientific and technical journal of SPbFPU. Informatics. Telecommunications. Management. SPb, 3(174) 2013

[3] I. Vasilev. The model of container to railcar discharge process on the container terminal. «Informatization and communication» journal, №3, 2011. P. 54-56. 